\title{
General Aspects and Recent Advances on Bacterial Protein Toxins
}

\author{
Emmanuel Lemichez ${ }^{1}$ and Joseph T. Barbieri ${ }^{2}$ \\ ${ }^{1}$ INSERM, U1065, Centre Méditerranéen de Médecine Moléculaire, Microbial Toxins in Host-Pathogen \\ Interactions, C3M, Université de Nice-Sophia-Antipolis, UFR Médecine, 06204 Nice, France \\ ${ }^{2}$ Medical College of Wisconsin, Microbiology and Molecular Genetics, Milwaukee, Wisconsin 53151 \\ Correspondence: lemichez@unice.fr
}

\begin{abstract}
Bacterial pathogens produce protein toxins to influence host-pathogen interactions and tip the outcome of these encounters toward the benefit of the pathogen. Protein toxins modify host-specific targets through posttranslational modifications (PTMs) or noncovalent interactions that may inhibit or activate host cell physiology to benefit the pathogen. Recent advances have identified new PTMs and host targets for toxin action. Understanding the mechanisms of toxin action provides a basis to develop vaccines and therapies to combat bacterial pathogens and to develop new strategies to use toxin derivatives for the treatment of human disease.
\end{abstract}

$\mathrm{D}$ uring the dialogue established between bacterial pathogens and their host, secreted protein toxins play a key role in the specificity of the outcome of the infection. These toxins are fascinating objects if one considers that in some instances injection of small amounts of these purified proteins recapitulates the deadly symptoms of the infection, such as in the case of the spastic paralysis triggered by tetanus neurotoxin (TeNT). Here we will briefly introduce the diversity of bacterial protein toxins and then focus on new advances made on toxins acting on intracellular host targets.

Bacterial protein toxins can be classified into several functional groups despite their diverse structures and modes of action (Fig. 1) (for general reviews, see Alouf and Popoff 2006). These groups are:
1. A group of toxins that act directly on host cell plasma membrane receptors. By acting as host receptor agonists or antagonists, they corrupt signal transduction pathways. For instance, superantigens produced by staphylococci can bridge nonspecifically major histocompatibility complex class II at the surface of antigen-presenting cells with the T-cell receptor, leading to a nonclonal activation of immune cells and resulting in inflammatory storms (Alouf and Popoff 2006).

2. A group of toxins that disrupt membrane lipid bilayer integrity by forming pores of different size and molecular selectivity or because of their phospholipase activity (Bischofberger et al. 2009). For example, the poreforming toxin listeriolysin O (LLO) produced by bacteria internalized into phagocytic com-

Editors: Pascale Cossart and Stanley Maloy

Additional Perspectives on Bacterial Pathogenesis available at www.perspectivesinmedicine.org

Copyright (C) 2013 Cold Spring Harbor Laboratory Press; all rights reserved; doi: 10.1101/cshperspect.a013573

Cite this article as Cold Spring Harb Perspect Med 2013;3:a013573 
E. Lemichez and J.T. Barbieri

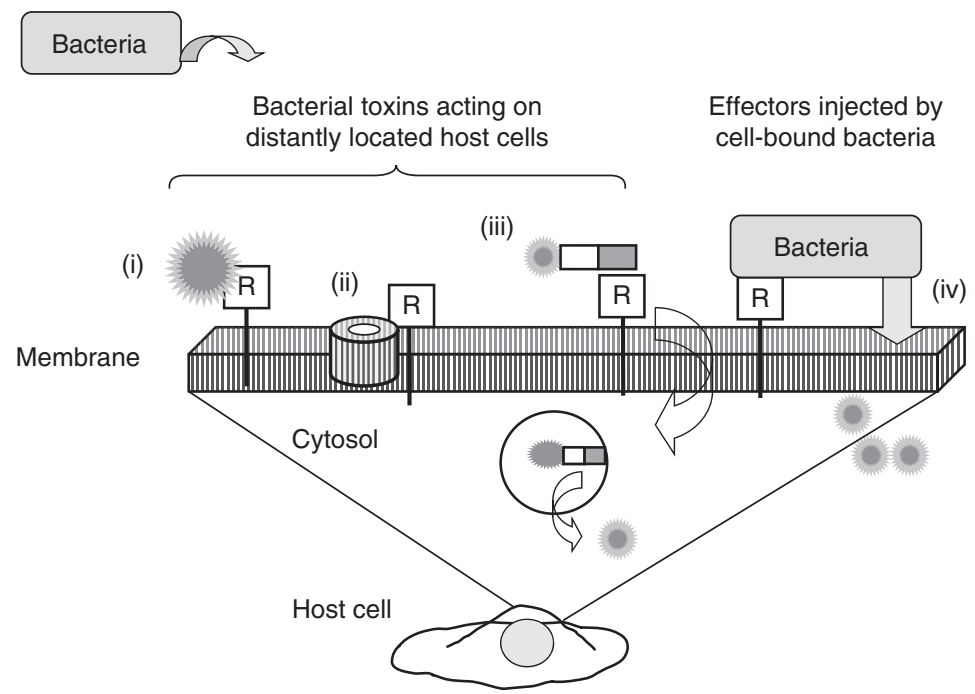

Figure 1. Classes of bacterial protein toxins. There are four major classes of bacterial toxins, including (i) toxins that bind to the surface of host cell plasma membrane receptors and modify host cell physiology by triggering intracellular signaling; (ii) toxins that bind to host cell plasma membranes and disrupt the membrane lipid bilayer through pore formation or expression of phospholipase activity; (iii) AB toxins with an A domain that possesses enzymatic activity and a B domain that binds and enters the host cell; and (iv) toxins with an enzymatic activity that is delivered into the host cell by an injection apparatus that is a component of the bacterial pathogens, which include the type III secreted cytotoxins. The first three groups of toxins often act at a site within the host that is distant from the bacterial pathogen, whereas type III secreted cytotoxins are delivered into the host cell directly by the bacterium, often paralyzing the host cell's ability to neutralize the bacterial pathogen.

partments disrupts the phagosomal membrane, releasing bacteria into the cytosol for dissemination (Cossart 2011). In addition, loss of plasma membrane integrity by poreforming toxins corrupts cell signaling (Bischofberger et al. 2009; Cossart 2011).

3. A group of toxins that inject toxic enzymatic components into distant host cells once they have entered cells by receptor-mediated endocytosis. These sophisticated proteins can be functionally described as molecular syringes (Fig. 1). They are termed $A B$ toxins because of the presence of a polypeptidic A domain that possesses enzymatic activity and one or more B domains that bind and enter the host cell. These toxins, such as TeNT and botulinum neurotoxins (BoNTs), are frequently endowed with a major virulent function. Therefore, these proteins are of major interest in the study of bacterial virulence mechanisms, such as transfer of virulence genes among bacteria, regulation of virulence factor expression, and the secretion apparatuses of these virulence factors. In addition, they represent valuable tools to study cell biological processes, that is: (1) receptor endocytosis and vesicular trafficking, such as the retrograde transport of Shiga toxin (Stx) from the surface to the endoplasmic reticulum (ER); (2) translocation of their enzymatic domain through intracellular membranes; and (3) the regulation and function of their cellular targets, as reviewed here (Fig. 2). Finally, it is of major interest to use these potent factors as medical tools, for instance, to kill cancer cells as well as to boost immune responses for vaccination.

4. A group of toxins that are synthesized within the bacterium and delivered directly into the host cell by an injection needle, including type III secreted cytotoxins of Gram-negative bacteria (Fig. 1) (Galan 2009). The type III delivery apparatus is derived by gene duplication from the flagellum apparatus. 


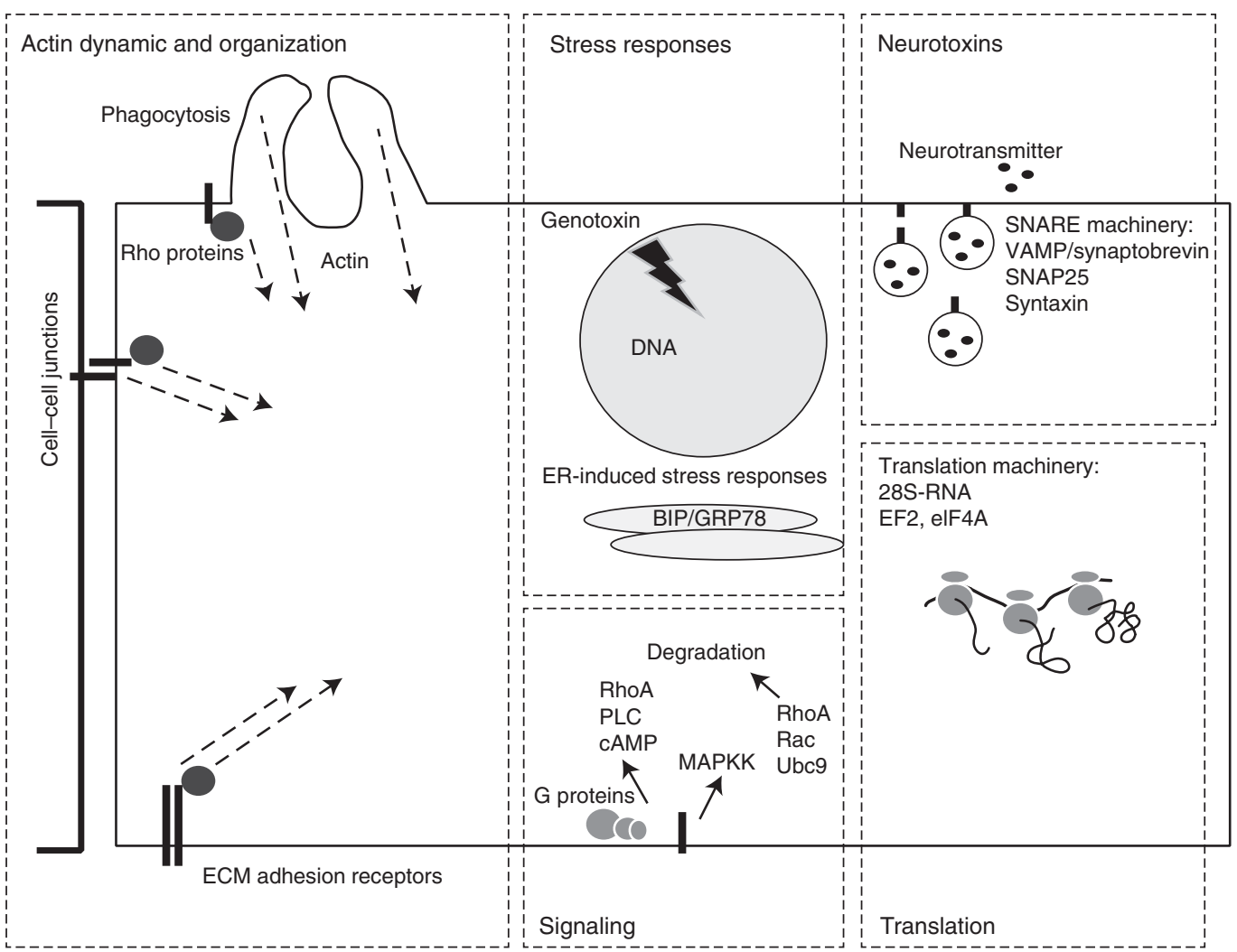

Figure 2. Cellular Achilles' heels targeted by bacterial toxins. Despite differences in provenance, structure, or enzymatic activities, potent bacterial toxins known to date target conserved key cellular factors and pathways (see Table 1 for details). (1) Several toxins directly target actin or Rho GTPases, upstream regulators of the actomyosin cytoskeleton organization and dynamic. These toxins have a major impact on cell-cell or cellmatrix adhesion, motility, and phagocytosis. (2) One group of toxins triggers stress responses, for example, by catalyzing DNA damage. (3) Neurotoxins directly cleave components of the SNARE machinery, thereby impairing exocytosis of neurotransmitters. (4) Several toxins impair cell translation by targeting ribosomal RNA or translation factors (eIF4A or EF2). (5) Other toxins corrupt major signaling pathways, notably resulting in high level of production of cAMP or a shutdown of MAP kinase signaling. They also exacerbate the destruction of signaling molecules, such as Ubc9, RhoA, and Rac1.

These cytotoxins (also called effectors) possess a catalytic activity that covalently modifies a host protein through a posttranslational modification (PTM) or through a noncovalent interaction. These cytotoxins are unique in that the bacterium delivers a large amount of molecules over a short period of time to overwhelm the physiology of the host cell. For example, Salmonella spp. inject SopE, a guanine nucleotide exchange factor that stimulates Rac GTPase activity to facilitate entry into pathogen-associated vacuoles in epithelial cells (Galan 2009).

\section{TOXINS TARGETING ACTIN AND SMALL RHO GTPASES}

A large number of potent bacterial toxins, notably those produced by several Clostridium spp., such as Clostridium difficile, and some pathogenic Gram-negative bacteria, such as uropathogenic strains of Escherichia coli, catalyze PTM of components of the cell actomyosin cytoskeleton (Table 1). The actomyosin cytoskeleton confers on host cells their shape and membrane dynamics. This function is required for cells to properly control their adhesion to 


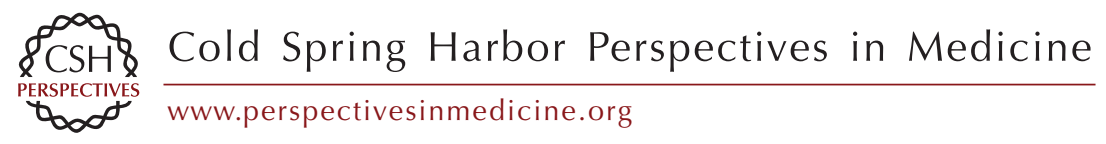

Table 1. Bacterial enzymatic toxins acting on host cell cytosolic factors

\begin{tabular}{|c|c|c|c|c|c|}
\hline Toxin & Target & Activity & Effect & Bacteria & Reference \\
\hline \multicolumn{6}{|c|}{ Toxins targeting actin cytoskeleton components } \\
\hline $\mathrm{C} 2$ & Actin R177 & ADP-ribosylation & Depolymerization & Clostridium botulinum & Aktories et al. 1986 \\
\hline Iota & Actin R177 & ADP-ribosylation & Depolymerization & Clostridium perfringens & Aktories et al. 2011 \\
\hline CDT & Actin R177 & ADP-ribosylation & Depolymerization & Clostridium difficile & Aktories et al. 2011 \\
\hline CST & Actin R177 & ADP-ribosylation & Depolymerization & Clostridium spiroforme & Aktories et al. 2011 \\
\hline VIP & Actin R177 & ADP-ribosylation & Depolymerization & Bacillus cereus & Aktories et al. 2011 \\
\hline $\begin{array}{l}\text { Tc }(\text { TccC3- } \\
\text { subunit })\end{array}$ & Actin T148 & ADP-ribosylation & Actin clustering & Photorhabdus luminescens & Lang et al. 2010 \\
\hline $\begin{array}{l}\text { MARTXvc (ACD } \\
\text { domain) }\end{array}$ & Actin $\mathrm{K} 50-$ actin E270 & Actin cross-linking & Depolymerization & Vibrio cholerae & Aktories et al. 2011 \\
\hline $\mathrm{CNF} 1,-2,-3$ & $\begin{array}{l}\text { Rac1, RhoA, Cdc42 (Q61 } \\
\quad \text { or Q63) }\end{array}$ & Deamidase & Actin polymerization & Escherichia coli & Lemonnier et al. 2007 \\
\hline CNFy & RhoA (Q63) & Deamidase & Actin polymerization & Yersinia pseudotuberculosis & Hoffmann et al. 2004 \\
\hline DNT & $\begin{array}{l}\text { Rac1, RhoA, Cdc42 (Q61 } \\
\text { or Q63) }\end{array}$ & Transglutaminase/deamidase & Actin polymerization & $\begin{array}{l}\text { Bordetella pertussis, } \\
\quad \text { Bordetella parapertussis }\end{array}$ & Lemonnier et al. 2007 \\
\hline C3 and C3-like & RhoA (N41) & ADP-ribosyltransferase & $\begin{array}{l}\text { Actin cable } \\
\text { depolymerization }\end{array}$ & $\begin{array}{l}\text { C. botulinum, Clostridium } \\
\text { limosum, B. cereus, } \\
\text { Staphylococcus aureus }\end{array}$ & Aktories 2011 \\
\hline TcdA and TcdB & Rho GTPases (T35 or T37) & Glucosylation (UDP-glucose) & Actin depolymerization & C. difficile & Just et al. 1995 \\
\hline HT & Rho GTPases (T35 or T37) & Glucosylation (UDP-glucose) & Actin depolymerization & Clostridium sordellii & Aktories 2011 \\
\hline LT & Ras GTPases, Rac (T35) & Glucosylation (UDP-glucose) & Actin depolymerization & C. sordellii & Aktories 2011 \\
\hline$\alpha$-Toxin & Rho GTPases (T35 or T37) & $\begin{array}{l}N \text {-Acetyl-glucosamination } \\
\quad \text { (UDP- } N \text { - } \\
\text { acetylglucosamine) }\end{array}$ & Actin depolymerization & Clostridium novyi & Aktories 2011 \\
\hline TpeL & Ras GTPases, Rac (T35) & $\begin{array}{l}N \text {-Acetyl-glucosamination } \\
\quad \text { (UDP- } N \text { - } \\
\text { acetylglucosamine) }\end{array}$ & Actin depolymerization & C. perfrigens & Aktories 2011 \\
\hline lbpA & Rho GTPases (Y32 or Y34) & Adenylylation (AMPylation) & Actin depolymerization & Histophilus somni & Worby et al. 2009 \\
\hline Tc (TccC5 & Rho GTPases (Q61 & ADP-ribosylation & Actin polymerization & P. luminescens & Lang et al. 2010 \\
\hline
\end{tabular}

subunit)

or Q63) 


\section{Toxins corrupting ubiquitin and ubiquitin-like signaling}

LLO Cellular membranes Pore-forming tox

CNF1

RhoA

Deamidase

CNF1

Racl

Deamidase

\section{Toxins targeting cell translational machinery}

DT

$$
\text { EF2 (diphthamide-715) }
$$

ADP-ribosylation

ETA

EF2 (diphthamide-715) ADP-ribosylation

Stx

$28 \mathrm{~S}$ ribosomal RNA

$N$-Glycosidase

(adenine base at

position 4324)

Stx-like $(1,1 c, 2$,

28 S ribosomal RNA

N-Glycosidase

$2 \mathrm{c}, 2 \mathrm{~d}, 2 \mathrm{e}, 2 \mathrm{f}$

LT-1 (BPSL1549) eIF4A (Q339)

\section{Toxins targeting SNARE machinery}

$\begin{array}{lll}\text { TeNT } & \text { VAMP/synaptobrevin } & \text { Zinc metalloprotease } \\ \text { BoNT A, E } & \text { SNAP25 } & \text { Zinc metalloprotease } \\ \text { BoNT B, D, F, G } & \text { VAMP/synaptobrevin } & \text { Zinc metalloprotease } \\ \text { BoNT C } & \text { SNAP25, syntaxin } & \text { Zinc metalloprotease }\end{array}$

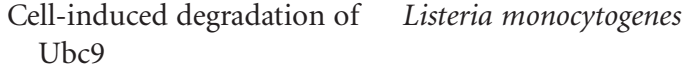

Smurf1-induced degradation of activated RhoA

HACE1 (XIAP, CIAP1/2) - E. col

induced degradation of

activated Rac1

Translation inhibition

Translation inhibition

Translation inhibition

Translation inhibition

Translation inhibition (uncouples ATPase and

helicase activities)

Neurotransmission inhibition Clostridium tetan

Neurotransmission inhibition C. botulinum

Neurotransmission inhibition C. botulinum

Neurotransmission inhibition C. botulinum

\section{Corynebacterium}

diphtheriae

Pseudomonas aeruginosa

Shigella dysenteriae

Shigatoxigenic E. coli

Burkholderia pseudomall

Cell cycle arrest

Cell cycle arrest

Cell cycle arrest

Cell cycle arrest

(lymphocyte apoptosis)

Cell cycle arrest

Cell cycle arrest

ER stress responses
E. coli

S. dysenteriae

Haemophilus ducreyi

Aggregatibacter

actinomycetemcomitans

Helicobacter hepaticus

Campylobacter jejuni

STEC
Ribet 2010

Visvikis 2010

Oberoi 2011; Torrino 2011

Murphy 2011

Murphy 2011

Johannes and Romer 2010

Johannes and Romer 2010

Cruz-Migoni et al. 2011

Hill et al. 2007

Hill et al. 2007

Hill et al. 2007

Hill et al. 2007

Ase-I-like (B s

Serine protease
Guerra et al. 2011

Guerra et al. 2011

Guerra et al. 2011

Shenker et al., 2007; Guerra et al. 2011

Guerra et al. 2011

Guerra et al. 2011

Byres et al. 2008
BIP/GRP78 


\section{$\$_{\mathrm{CSH}}^{\infty}$ Cold Spring Harbor Perspectives in Medicine \\ Wo}

\begin{tabular}{|c|c|c|c|c|c|}
\hline Toxin & Target & Activity & Effect & Bacteria & Reference \\
\hline \multicolumn{6}{|c|}{ Toxins targeting cAMP and MAP kinase signaling components } \\
\hline Ctx & $\mathrm{G} \alpha_{\mathrm{s}}(\mathrm{R} 201$, activation $)$ & ADP-ribosylation & cAMP induction & V. cholerae & Aktories et al. 2011 \\
\hline LT & $\mathrm{G} \alpha_{\mathrm{s}}(\mathrm{R} 201$, activation $)$ & ADP-ribosylation & cAMP induction & E. coli & Aktories et al. 2011 \\
\hline Ptx & $\mathrm{G}_{\mathrm{i}}(\mathrm{C} 351$, inactivation $)$ & ADP-ribosylation & cAMP induction & B. pertussis & Aktories et al. 2011 \\
\hline PMT & $\begin{array}{l}\mathrm{G} \alpha_{\mathrm{q}}, \mathrm{G} \alpha_{\mathrm{i}}, \mathrm{G} \alpha_{12 / 13} \\
\quad(\mathrm{Q} 209, \mathrm{Q} 205, \text { or Q226, } \\
\text { activation) }\end{array}$ & Deamidation & $\begin{array}{l}\text { cAMP inhibition, RhoA } \\
\text { activation, PLC activation }\end{array}$ & Pasteurella multocida & Aktories et al. 2011 \\
\hline ET & cAMP production & Adenylate cyclase & cAMP production & Bacillus anthracis & Leppla 1982 \\
\hline CyaA & cAMP production & Adenylate cyclase & cAMP production & B. pertussis & Ahuja et al. 2004 \\
\hline LT & $\begin{array}{l}\text { MAP kinase kinases } \\
\text { (except MEK5) }\end{array}$ & Metalloprotease & MAP kinase signaling & B. anthracis & $\begin{array}{l}\text { Collier and Young } \\
2003\end{array}$ \\
\hline
\end{tabular}

BoNT, botulinum neurotoxin; CDT, cytolethal distending toxin; CNF, cytotoxic necrotizing factor; CST, C. spiroforme toxin; Ctx, cholera toxin; DNT, dermonecrotic toxin; DT, diphtheria toxin; EF2, elongation factor-2; eIF, translation initiation factor; ET, edema toxin; ETA, exotoxin A; HT, hemorrhagic toxin; LLO, listeriolysin O; LT, lethal toxin; MAP, mitogen-activated protein; MARTX, multifunctional autoprocessing repeats-in-toxin; PLC, phospholipase C; PMT, P. multocida toxin; PTX, pertussis toxin; SNAP, synaptosomal-associated protein; SNARE, soluble $N$-ethylmaleimide-sensitive factor attachment protein receptor; Stx, Shiga toxin; Sub, subtilase toxin; TeNT, tetanus toxin; VAMP, vesicle-associated membrane protein; VIP, vegetative insecticidal protein. 
the matrix substratum and intercellular monolayer barrier integrity, as well as for immune cells to undergo migration and perform phagocytosis (Jaffe and Hall 2005). This group of bacterial weapons is thus particularly efficient for disruption of host epithelium barriers, for efficient bacterial dissemination, and for freezing distantly located immune cells to prevent both their migration to the site of infection and bactericidal action (Boquet and Lemichez 2003). Actomyosin cytoskeleton disruption by direct cross-linking of ADP-ribose on actin's arginine-177 residue is an enzymatic property of several clostridial toxins (Table 1) (Aktories et al. 1986, 2011). The ADP-ribosylated actin monomers are extremely toxic, although actin is a very abundant protein in cells. Indeed, ADP-ribosylated actin monomers act dominantly once incorporated into actin filaments by blocking addition of new monomers. This produces a disassembly of actin filaments, leading to cell retraction and collapse.

The property of disassembling actomyosin cytoskeleton is shared by several large clostridial toxins that modify Rho proteins (Aktories 2011). This group of key upstream regulators of actomyosin cytoskeleton organization and dynamic belongs to the superfamilly of small Ras GTPases (Jaffe and Hall 2005). Large glucosylating toxins catalyze the addition of a sugar molecule, such as glucose from UDP-glucose, on a key threonine residue of several small GTPases (Just et al. 1995). Addition of bulky glucose groups to this key amino acid residue poisons their biochemical activity and association with downstream effectors. Glucosylating toxins share as a common target Rac, a small Rho GTPase that orchestrates cellular innate immune responses against pathogens (Bokoch 2005; Boyer et al. 2011). This effector-binding domain of Rho proteins is subjected to several other PTMs by bacterial effectors and toxins, such as ADP-ribosylation and AMPylation (Table 1) (Worby et al. 2009; Yarbrough et al. 2009; Aktories 2011).

Photorhabdus luminescens organisms establish a symbiotic relationship with some entomopathogenic nematode species, conferring on them the capacity to kill susceptible insects. Exciting new findings on Tc toxin ( TccC3 and TccC5 subunits) of $P$. luminescens has shed light on two new toxin-mediated PTMs of actin and Rho GTPases (Lang et al. 2010). Hence, determination of the structure of the closely homologous Tc toxin of Yersinia pseudotuberculosis has revealed its organization into large multisubunit complexes (Landsberg et al. 2011). RhoA is ADP-ribosylated by TccC5 on glutamine-63 (Q61 for Rac and Cdc42) (Lang et al. 2010). This glutamine-63 residue is a hot spot of modification by bacterial toxins given its key function in catalyzing the hydrolysis of the guanosine triphosphate into guanosine diphosphate for switching GTPases to an inactive form (Flatau et al. 1997; Schmidt et al. 1997; Lemonnier et al. 2007). Thus, ADP-ribosylation of RhoA by TccC5 triggers its activation and the resulting formation of actin stress fibers (Lang et al. 2010). The TccC3 toxin subunit ADP-ribosylates actin on threonine-148 instead of arginine-177, as for other known actin-targeting toxins (Table 1). This modification blocks actin sequestration by thymosin$\beta 4$, thereby resulting in actin polymerization and aggregation of actin filament into clusters scattered through the cytosol. Intoxication of cells by both factors leads to an aggravation of actin reorganization into clusters because of the combined activation of Rho GTPases and actin polymerization.

\section{TOXINS CORRUPTING UBIQUITIN AND UBIQUITIN-LIKE SIGNALING}

An efficient way to interfere with the function of proteins is to catalyze their proteolysis. Some bacterial metalloprotease toxins such as the lethal factor of Bacillus anthracis and the neurotoxins of clostridia directly catalyze the endoproteolytic cleavage of key host proteins (Table 1). Recent advances also indicate that some bacterial toxins exacerbate cellular protein degradation by the ubiquitin/proteasomal system (UPS) (Munro et al. 2007). PTM of proteins by ubiquitin and ubiquitin-like molecules, such as SUMO or NEDD8, control the fate and activity of large numbers of proteins and 
are targeted by numerous bacterial virulence factors (Munro et al. 2007). The ubiquitylation reaction consists of the covalent attachment of ubiquitin, an $8-\mathrm{kDa}$ polypeptide, to lysine residues on the target protein (Weissman 2001). This involves a cascade of transfer reactions between ubiquitin carrier proteins. Among these factors, the E3 ubiquitin ligase enzymes confer the specificity to the reaction by binding distinctively to a panel of target proteins. Additional molecules of ubiquitin can be subsequently attached to one of the seven lysines of the previously cross-linked ubiquitin molecule, leading to the formation of various types of mono-, multi-, or polyubiquitin chain assemblies, notably lysine-48 (K48) polyubiquitin chains for substrate targeting to proteasomal destruction (Dikic et al. 2009). Several toxins, by catalyzing the permanent activation of Rho proteins, in fact exacerbate the cellular UPSmediated regulation of these GTPases (Doye et al. 2002; Visvikis et al. 2010). This represents a remarkable example of how toxins can be useful to unravel new cellular regulations and determine in this case E3 ubiquitin ligases that are responsible for Rho protein ubiquitylation. For instance, the study of cytotoxic necrotizing factor 1 (CNF1) recently revealed the critical function of HACE1 and implicated XIAP and cIAP1, E3 ubiquitin ligases, in the targeting of Rac1 to UPS (Oberoi et al. 2011; Torrino et al. 2011). The importance of UPS regulation of Rho proteins during infection remains to be fully determined, although it likely fosters endothelium invasion by bacteria (Doye et al. 2002; Torrino et al. 2011). In addition, some toxins target ubiquitin-like molecules. For instance, Listeria listeriolysin $\mathrm{O}$ acts on distant host cells to stimulate the degradation of Ubc9, a key enzyme of protein modification by SUMOylation (Ribet et al. 2010). Although bacterial toxins interfere only indirectly with UPS regulation of host cell proteins, several bacterial effectors catalyze a direct PTM of ubiquitin and ubiquitin-like molecules. Indeed, the type III secreted effectors CHBP from Burkholderia pseudomallei and Cif from enteropathogenic E. coli deamidate the ubiquitin-like protein NEDD8 (Cui et al. 2010; Taieb et al. 2011). This abolishes the activity of multimeric Cullin-RING ubiquitin ligases and impairs numerous major signaling pathways.

\section{TOXINS TARGETING CELL TRANSLATIONAL MACHINERY}

An efficient way to kill host cells is through inhibition of protein synthesis. Several pathogenic bacteria share the capacity to inhibit protein translation by PTM of translational factors, as, for example, elongation factor-2 (EF2), which is ADP-ribosylated by diphtheria toxin (DT) of Corynebacterium diphtheriae and exotoxin A (ETA) of Pseudomonas aeruginosa (Table 1) (Murphy 2011). Both DTand ETA target a PTM-modified histidine residue of EF2 called diphthamide, which is only present in eukaryotes and archaea (Zhang et al. 2010). Most recently, a report shows that the lethal toxin of B. pseudomallei (BPSL1549) targets the translation initiation factor 4A (eIF4A) (Cruz-Migoni et al. 2011). This toxin belongs to the growing family of deamidase virulence factors first identified for CNF1 toxin, converting a specific target glutamine into a glutamic acid residue (Flatau et al. 1997; Schmidt et al. 1997; Cui et al. 2010). Despite an absence of primary sequence homology with the CNF1 deamidase domain, BPSL1549 possesses a conservation of the amino acid residues within the catalytic site. The deamidase activity of BPSL1549 toward eIF4A glutamine-339 has an inhibitory effect on the helicase activity, thereby blocking translation (Cruz-Migoni et al. 2011).

The group of Stx and Shiga-like $N$-glycosidase toxins of Shigella dysenteriae and enterohemorrhagic strains of E. coli remove a specific adenine from $28 \mathrm{~S}$ ribosomal RNA (Table 1) (Johannes and Romer 2010). Stx toxins play key role in the induction of hemolytic uremic syndrome and at sublethal doses induced inflammatory reactions (Sandvig et al. 1992; Johannes and Romer 2010). A remarkable property of these toxins is their ability to enter cells by triggering membrane deformation at high concentration and undergo a retrograde transport to the ER, where the catalytic domain exits to the cytosol by hijacking the ER-associated 
degradation machinery (Sandvig et al. 1992; Johannes and Romer 2010).

\section{TOXINS TARGETING SNARE MACHINERY}

The clostridial neurotoxins (CNTs) include TeNT and the BoNTs, which are the most toxic proteins for humans but are also commonly used therapy for many human neurological disorders (Table 1). The neurologic specificity of the CNTs lies in their ability to bind neuronspecific receptors and then cleave neuron-specific soluble $N$-ethylmaleimide-sensitive factor attachment protein receptor (SNARE) proteins. These highly specific interactions between BoNTs and synaptic vesicle proteins have been recently reviewed (Brunger et al. 2008). There are seven BoNTserotypes (A-G), and each serotype cleaves one or more proteins within the SNARE protein complex (Hill et al. 2007). SNARE protein cleavage inhibits neurotransmitter vesicle fusion to the plasma membrane and subsequent release of neurotransmitters. The unique pathologies elicited by TeNT and BoNTs are due to their intracellular trafficking in neurons. BoNTs bind gangliosides on resting motor neurons at the neuromuscular junction and enter neurons within cycling synaptic vesicles. SV2 is the protein receptor for BoNT A (Dong et al. 2006). Upon acidification of the synaptic vesicle, the catalytic domain of the BoNTs translocates into the cytoplasm to cleave SNARE proteins and inhibit neurotransmitter release at the neuromuscular junction to elicit flaccid paralysis. In contrast, TeNT binds gangliosides on the cell surface of resting motor neurons and enters endosomes that transcytose TeNT into the central nervous system, where TeNT enters inhibitory neurons to block neurotransmitter release and elicit spastic paralysis. TeNTappears to be transported via a novel neuronal compartment through specialized $\mathrm{pH}$ regulation (Bohnert and Schiavo 2005; Chen et al. 2009).

\section{TOXINS TARGETING DNA AND INDUCING ER STRESS RESPONSES}

In addition to playing key roles during infection, in some cases bacterial toxins may repre- sent risk factors for cancer (Collins et al. 2011). For example, the genotoxic activity of cytolethal distending toxins (CDTs), a group of toxins produced by a large number of Gram-negative pathogenic bacteria, likely represents a risk factor for carcinogenesis (Table 1) (Lara-Tejero and Galan 2000; Guerra et al. 2011). Structural analysis of Haemophilus ducreyi CDT (HdCDT) shows interactions between the three globular subunits (CdtA, -B, and -C) (Nesic et al. 2004). CdtA and CdtC adopt a lectin-type conformation, with structural homologies with the cellbinding subunit of the plant toxin ricin, and with affinity to sphingomyelin. The catalytic subunit CdtB shares conserved amino acid residues with the active site of mammalian deoxyribonuclease (DNase) I (Lara-Tejero and Galan 2000) at residues that contribute to cleavage of the phosphodiester bond of DNA and within a pentapeptide motif (Elwell and Dreyfus 2000). Hence, CdtB of Aggregatibacter actinomycetemcomitans bears a phosphatidylinositol 3,4,5triphosphate 5-phosphatase enzymatic activity, similar to that of PTEN or SHIP1 (Shenker et al. 2007). The relative contribution of both biochemical activities in CdtB-induced DNA damage responses, $G_{2} \mathrm{M}$ cell cycle arrest, and cell death may vary depending on cell types (for review, see Guerra et al. 2011).

\section{TOXINS TARGETING CAMP SIGNALING COMPONENTS}

Several pathogenic bacteria have evolved toxins to manipulate the cellular flux of cAMP (Table 1). This comprises $\mathrm{Ca}^{2+} /$ calmodulindependent adenylate cyclase toxins producing cAMP from ATP, such as edema toxin (ET) of B. anthracis, as well as a group of toxins targeting heterotrimeric $G$ proteins, such as cholera toxin of Vibrio cholera and pertussis toxin of Bordetella pertussis (Table 1) (Ahuja et al. 2004). cAMP is a crucial mediator of cell signaling and is thus implicated in numerous cell biological and physiological functions through the activation of effector proteins such as protein kinase $\mathrm{A}$ and the Rap1 exchange factor EPAC. Consistently, manipulation of cAMP signaling confers on bacteria a large panel of features. For example, a recent 
study shed light on how ET of $B$. anthracis manipulates macrophage genetic responses (Kim et al. 2008). Production of cAMP leads to a reprogramming of macrophage transcription toward a genetic program with close similarities to anti-inflammatory G-protein-coupled receptors, for induction of inflammation resolution, a phenomenon requiring active cell signaling (Kim et al. 2008). This comprises a CREBand syndecan-1-dependent induction of macrophage motility and vascular endothelial growth factor-triggered lymphangiogenesis. Toxins inducing cAMP flux (notably cholera toxin) are used to manipulate immune responses, a feature that is also under study for Rho-activating toxins, to develop potent immunoadjuvants for mucosal vaccination (Munro et al. 2005; Fabbri et al. 2008).

Recent advances have determined that ET and lethal toxin (LT) of B. anthracis directly target endothelial cell actin cytoskeleton and corrupt the proper localization of adherens junction molecules, effects that likely account for the major vascular dysfunctions resulting from anthrax infection or toxemia (Guichard et al. 2010; Lemichez et al. 2010; Maddugoda et al. 2011). At early time periods of endothelial cell infection or intoxication, ET has a dominant effect over LT, inducing the formation of transendothelial cell macroaperture tunnels $\sim 10 \mu \mathrm{m}$ in diameter (Maddugoda et al. 2011). Formation of these transcellular tunnels likely contributes to the rupture of endothelium barrier function and triggers edema that is particularly visible in the intestine of mice intoxicated by ET (Maddugoda et al. 2011). The tunnels are induced by a group of toxins and exoenzymes, now referred to as tunnel-forming toxins, also comprising the RhoA ADP-ribosyltranferase EDIN of Staphylococcus aureus (Boyer et al. 2006; Lemichez et al. 2010). LT, through its proteolytic activity toward mitogen-associated protein (MAP) kinase kinases, induces at late time periods of intoxication the formation of thick actin cables, compromising endothelial cell junction integrity and possibly the viability of some endothelial cell types (Rolando et al. 2010). Rupture of endothelial cell junctions by both toxins at late time periods of intoxication also involves the targeting of the Rab11/Sec15 exocyst components, thereby inhibiting the recycling pathways for proper localization of the vascular endothelial cadherin critical adherens junction molecule at cell-cell junctions (Guichard et al. 2010).

\section{TOWARD DECIPHERING THE ROLE OF TOXINS DURING THE COURSE OF BACTERIAL INFECTION}

Major challenges to date consist in defining how toxins affect differentiated host cell types in order to define their contribution to the various steps of the infection process. This exciting challenge is rendered possible by defining toxins' biochemical activities, as described above. New challenges include the identification of host cell toxin receptors, a major determinant of host species and cell type specificity. The importance of receptor specificity was recently presented, whereby humans do not synthesize sialic acid $N$-glycolylneuraminic acid but metabolize this monosaccharide, which is abundant in some food products, thereby becoming susceptible to the subtilase toxin (SubAB) (Byres et al. 2008). This toxin is produced by some strains of the shigatoxigenic group of E. coli (STEC) associated with severe forms of hemolytic uremic syndrome.

Determination of the toxin's mode of action requires characterizing host cell receptors. For example, a difference of a few amino acid residues between mouse and human precursors of a heparin-binding epidermal growth factor-like growth factor (HB-EGF) defines resistance in mice to diphtheria toxin (Naglich et al. 1992). The use of new screening methods to define host factors involved in cell intoxication will certainly accelerate the identification of host factor receptors. Notably, the use of gene-trap retrovirus-driven insertional mutagenesis to produce a collection of null-allele cell mutants for screening (Carette et al. 2009) will help identify toxin receptors and also help define host factors involved in facilitating toxin enzymatic domains' translocation and activation into the host cell cytosol, as well as toxin cofactors. Such an elegant strategy identified TMEM181 as the host 
Bacterial Protein Toxins

cell receptor of HdCDT, together with sphingomyelin synthase-1, an enzymatic activity likely required to maintain proper organization of lipid rafts (Carette et al. 2009). Similarly, the lipolysis-stimulated lipoprotein receptor has also been recently identified as the receptor of the binary actin ADP-ribosylating toxin of hypervirulent strains of $C$. difficile (Papatheodorou et al. 2011).

An approach of major interest, although probably highly counterintuitive, is to define conditions in which bacterial toxins can trigger host antimicrobial responses and thus exert local or cell-type-specific "avirulence" effects. This likely will help decipher how the host senses and reacts properly to pathogenic bacteria rather than to commensals (Sansonetti 2011). One such interesting example is the infection of macrophages by LT of B. anthracis (Ali et al. 2011). The lethal factor enzymatic component of this toxin penetrates cells and cleaves the amino-terminal part of MAP kinase kinases, interrupting these signaling pathways (Duesbery et al. 1998). This induces a leakage of ATP through connexin channels as a result of impaired p38 MAP kinase kinase and AKT signaling pathways (Ali et al. 2011). Next, the sensing of extracellular ATP via $\mathrm{P}_{2} \mathrm{X}_{7}$ purinergic receptors leads to activation of the inflammasome system and the production of interleukin$1 \beta$, a critical factor in mounting antibacterial responses (Ali et al. 2011). Sensing of ATP leakage and potassium efflux induced by several pore-forming toxins are likely critical elements allowing host cells to properly decipher between commensal and pathogenic bacteria-producing toxins (Ali et al. 2011; Hamon and Cossart 2011). Also in line with this, a recent study conducted in Drosophila revealed that direct activation of Rac activity by the CNF1 toxin of uropathogenic E. coli triggers an antimicrobial response via Rip kinase (IMD in flies) (Boyer et al. 2011). Importantly, recombinant insects expressing CNF1 become resistant to infection by Pseudomonas entomopathogenic bacteria. This indicates that some bacterial toxins may favor infection of the host at specific stages, while triggering antimicrobial responses in other contexts.

\section{CONCLUDING REMARKS}

Protein toxins provide the bacterium with an advantage in host-pathogen interactions. Each protein toxin appears unique and provides the producing bacterial pathogen with a selective advantage in these host-pathogen interactions. Continued studies on these protein toxins will extend our understanding of bacterial pathogenesis and may identify novel applications of these toxins as therapies to treat human disease.

\section{ACKNOWLEDGMENTS}

E.L. is supported by institutional funding from INSERM and grants from Foundation Infectiopôle Sud, the Agence Nationale de la Recherche (ANR 11BSV3 004 01), and the Association pour la Recherche sur le Cancer (ARC SFI20 111203659). J.T.B. is supported by a grant from the National Institutes of Health (AI30 162) and is a member of the Great Lakes Regions Center of Excellence (AIU54-057153). We apologize to colleagues whose important contributions could not be cited because of space limitations.

\section{REFERENCES}

Ahuja N, Kumar P, Bhatnagar R. 2004. The adenylate cyclase toxins. Crit Rev Microbiol 30: 187-196.

Aktories K. 2011. Bacterial protein toxins that modify host regulatory GTPases. Nat Rev Microbiol 9: 487-498.

Aktories K, Barmann M, Ohishi I, Tsuyama S, Jakobs KH, Habermann E. 1986. Botulinum C2 toxin ADP-ribosylates actin. Nature 322: 390-392.

Aktories K, Lang AE, Schwan C, Mannherz HG. 2011. Actin as target for modification by bacterial protein toxins. FEBS J 278: 4526-4543.

Ali SR, Timmer AM, Bilgrami S, Park EJ, Eckmann L, Nizet V, Karin M. 2011. Anthrax toxin induces macrophage death by p38 MAPK inhibition but leads to inflammasome activation via ATP leakage. Immunity 35: 34-44.

Alouf JE, Popoff MR, ed. 2006. The comprehensive sourcebook of bacterial protein toxins, 3rd ed. Elsevier, Amsterdam, The Netherlands.

Bischofberger M, Gonzalez MR, van der Goot FG. 2009. Membrane injury by pore-forming proteins. Curr Opin Cell Biol 21: 589-595.

Bohnert S, Schiavo G. 2005. Tetanus toxin is transported in a novel neuronal compartment characterized by a specialized pH regulation. J Biol Chem 280: 42336-42344.

Bokoch GM. 2005. Regulation of innate immunity by Rho GTPases. Trends Cell Biol 15: 163-171. 
E. Lemichez and J.T. Barbieri

Boquet P, Lemichez E. 2003. Bacterial virulence factors targeting Rho GTPases: Parasitism or symbiosis? Trends Cell Biol 13: 238-246.

Boyer L, Doye A, Rolando M, Flatau G, Munro P, Gounon P, Clement R, Pulcini C, Popoff MR, Mettouchi A, et al. 2006. Induction of transient macroapertures in endothelial cells through RhoA inhibition by Staphylococcus aureus factors. J Cell Biol 173: 809-819.

Boyer L, Magoc L, Dejardin S, Cappillino M, Paquette N, Hinault C, Charriere GM, Ip WK, Fracchia S, Hennessy E, et al. 2011. Pathogen-derived effectors trigger protective immunity via activation of the Rac2 enzyme and the IMD or Rip kinase signaling pathway. Immunity 35: 536-549.

Brunger AT, Jin R, Breidenbach MA. 2008. Highly specific interactions between botulinum neurotoxins and synaptic vesicle proteins. Cell Mol Life Sci 65: 2296-2306.

Byres E, Paton AW, Paton JC, Lofling JC, Smith DF, Wilce MC, Talbot UM, Chong DC, Yu H, Huang S, et al. 2008. Incorporation of a non-human glycan mediates human susceptibility to a bacterial toxin. Nature 456 : 648-652.

Carette JE, Guimaraes CP, Varadarajan M, Park AS, Wuethrich I, Godarova A, Kotecki M, Cochran BH, Spooner E, Ploegh HL, et al. 2009. Haploid genetic screens in human cells identify host factors used by pathogens. Science 326: 1231-1235.

Chen C, Fu Z, Kim JJ, Barbieri JT, Baldwin MR. 2009. Gangliosides as high affinity receptors for tetanus neurotoxin. J Biol Chem 284: 26569-26577.

Collier RJ, Young JA. 2003. Anthrax toxin. Annu Rev Cell Dev Biol 19: 45-70.

Collins D, Hogan AM, Winter DC. 2011. Microbial and viral pathogens in colorectal cancer. Lancet Oncol 12: 504512.

Cossart P. 2011. Illuminating the landscape of host-pathogen interactions with the bacterium Listeria monocytogenes. Proc Natl Acad Sci 108: 19484-19491.

Cruz-Migoni A, Hautbergue GM, Artymiuk PJ, Baker PJ, Bokori-Brown M, Chang CT, Dickman MJ, EssexLopresti A, Harding SV, Mahadi NM, et al. 2011. A Burkholderia pseudomallei toxin inhibits helicase activity of translation factor eIF4A. Science 334: 821-824.

Cui J, Yao Q, Li S, Ding X, Lu Q, Mao H, Liu L, Zheng N, Chen S, Shao F. 2010. Glutamine deamidation and dysfunction of ubiquitin/NEDD8 induced by a bacterial effector family. Science 329: 1215-1218.

Dikic I, Wakatsuki S, Walters KJ. 2009. Ubiquitin-binding domains-From structures to functions. Nat Rev Mol Cell Biol 10: 659-671.

Dong M, Yeh F, Tepp WH, Dean C, Johnson EA, Janz R, Chapman ER. 2006. SV2 is the protein receptor for botulinum neurotoxin A. Science 312: 592-596.

Doye A, Mettouchi A, Bossis G, Clement R, BuissonTouati C, Flatau G, Gagnoux L, Piechaczyk M, Boquet P, Lemichez E. 2002. CNF1 exploits the ubiquitin-proteasome machinery to restrict Rho GTPase activation for bacterial host cell invasion. Cell 111: 553-564.

Duesbery NS, Webb CP, Leppla SH, Gordon VM, Klimpel KR, Copeland TD, Ahn NG, Oskarsson MK, Fukasawa K, Paull KD, et al. 1998. Proteolytic inactivation of
MAP-kinase-kinase by anthrax lethal factor. Science 280: 734-737.

Elwell CA, Dreyfus LA. 2000. DNase I homologous residues in $\mathrm{CdtB}$ are critical for cytolethal distending toxin-mediated cell cycle arrest. Mol Microbiol 37: 952-963.

Fabbri A, Travaglione S, Falzano L, Fiorentini C. 2008. Bacterial protein toxins: Current and potential clinical use. Curr Med Chem 15: 1116-1125.

Flatau G, Lemichez E, Gauthier M, Chardin P, Paris S, Fiorentini C, Boquet P. 1997. Toxin-induced activation of the $\mathrm{G}$ protein $\mathrm{p} 21$ Rho by deamidation of glutamine. Nature 387: 729-733.

Galan JE. 2009. Common themes in the design and function of bacterial effectors. Cell Host Microbe 5: 571-579.

Guerra L, Cortes-Bratti X, Guidi R, Frisan T. 2011. The biology of the cytolethal distending toxins. Toxins (Basel) 3: $172-190$.

Guichard A, McGillivray SM, Cruz-Moreno B, van Sorge NM, Nizet V, Bier E. 2010. Anthrax toxins cooperatively inhibit endocytic recycling by the Rab11/Sec15 exocyst. Nature 467: 854-858.

Hamon MA, Cossart P. 2011. $\mathrm{K}^{+}$efflux is required for histone $\mathrm{H} 3$ dephosphorylation by Listeria monocytogenes listeriolysin $\mathrm{O}$ and other pore-forming toxins. Infect Immun 79: 2839-2846.

Hill KK, Smith TJ, Helma CH, Ticknor LO, Foley BT, Svensson RT, Brown JL, Johnson EA, Smith LA, Okinaka RT, et al. 2007. Genetic diversity among botulinum neurotoxin-producing clostridial strains. J Bacteriol 189: 818-832.

Hoffmann C, Pop M, Leemhuis J, Schirmer J, Aktories K, Schmidt G. 2004. The Yersinia pseudotuberculosis cytotoxic necrotizing factor (CNFY) selectively activates RhoA. J Biol Chem 279: 16026-16032.

Jaffe AB, Hall A. 2005. Rho GTPases: Biochemistry and biology. Annu Rev Cell Dev Biol 21: 247-269.

Johannes L, Romer W. 2010. Shiga toxins-From cell biology to biomedical applications. Nat Rev Microbiol 8: 105-116.

Just I, Selzer J, Wilm M, von Eichel-Streiber C, Mann M, Aktories K. 1995. Glucosylation of Rho proteins by Clostridium difficile toxin B. Nature 375: 500-503.

Kim C, Wilcox-Adelman S, Sano Y, Tang WJ, Collier RJ, Park JM. 2008. Antiinflammatory cAMP signaling and cell migration genes co-opted by the anthrax bacillus. Proc Natl Acad Sci 105: 6150-6155.

Landsberg MJ, Jones SA, Rothnagel R, Busby JN, Marshall SD, Simpson RM, Lott JS, Hankamer B, Hurst MR. 2011. 3D structure of the Yersinia entomophaga toxin complex and implications for insecticidal activity. Proc Natl Acad Sci 108: 20544-20549.

Lang AE, Schmidt G, Schlosser A, Hey TD, Larrinua IM, Sheets JJ, Mannherz HG, Aktories K. 2010. Photorhabdus luminescens toxins ADP-ribosylate actin and RhoA to force actin clustering. Science 327: 1139-1142.

Lara-Tejero M, Galan JE. 2000. A bacterial toxin that controls cell cycle progression as a deoxyribonuclease I-like protein. Science 290: 354-357.

Lemichez E, Lecuit M, Nassif X, Bourdoulous S. 2010. Breaking the wall: Targeting of the endothelium by pathogenic bacteria. Nat Rev Microbiol 8: 93-104. 
Lemonnier M, Landraud L, Lemichez E. 2007. Rho GTPaseactivating bacterial toxins: From bacterial virulence regulation to eukaryotic cell biology. FEMS Microbiol Rev 31: 515-534.

Leppla SH. 1982. Anthrax toxin edema factor: A bacterial adenylate cyclase that increases cyclic AMP concentrations of eukaryotic cells. Proc Natl Acad Sci 79: 3162 3166.

Maddugoda MP, Stefani C, Gonzalez-Rodriguez D, Saarikangas J, Torrino S, Janel S, Munro P, Doye A, Prodon F Aurrand-Lions M, et al. 2011. cAMP signaling by anthrax edema toxin induces transendothelial cell tunnels, which are resealed by MIM via Arp2/3-driven actin polymerization. Cell Host Microbe 10: 464-474.

Munro P, Flatau G, Anjuere F, Hofman V, Czerkinsky C, Lemichez E. 2005. The Rho GTPase activators CNF1 and DNT bacterial toxins have mucosal adjuvant properties. Vaccine 23: 2551-2556.

Munro P, Flatau G, Lemichez E. 2007. Bacteria and the ubiquitin pathway. Curr Opin Microbiol 10: 39-46.

Murphy JR. 2011. Mechanism of diphtheria toxin catalytic domain delivery to the eukaryotic cell cytosol and the cellular factors that directly participate in the process. Toxins (Basel) 3: 294-308.

Naglich JG, Metherall JE, Russell DW, Eidels L. 1992. Expression cloning of a diphtheria toxin receptor: Identity with a heparin-binding EGF-like growth factor precursor. Cell 69: 1051-1061.

Nesic D, Hsu Y, Stebbins CE. 2004. Assembly and function of a bacterial genotoxin. Nature 429: 429-433.

Oberoi TK, Dogan T, Hocking JC, Scholz RP, Mooz J, Anderson CL, Karreman C, Meyer Zu Heringdorf D, Schmidt G, Ruonala M, et al. 2011. IAPs regulate the plasticity of cell migration by directly targeting Racl for degradation. EMBO J 31: 14-28.

Papatheodorou P, Carette JE, Bell GW, Schwan C, Guttenberg G, Brummelkamp TR, Aktories K. 2011. Lipolysis-stimulated lipoprotein receptor (LSR) is the host receptor for the binary toxin Clostridium difficile transferase (CDT). Proc Natl Acad Sci 108: 16422-16427.

Ribet D, Hamon M, Gouin E, Nahori MA, Impens F, NeyretKahn H, Gevaert K, Vandekerckhove J, Dejean A, Cossart P. 2010. Listeria monocytogenes impairs SUMOylation for efficient infection. Nature 464: 1192-1195.

Rolando M, Stefani C, Flatau G, Auberger P, Mettouchi A, Mhlanga M, Rapp U, Galmiche A, Lemichez E. 2010.
Transcriptome dysregulation by anthrax lethal toxin plays a key role in induction of human endothelial cell cytotoxicity. Cell Microbiol 12: 891-905.

Sandvig K, Garred O, Prydz K, Kozlov JV, Hansen SH, van Deurs B. 1992. Retrograde transport of endocytosed Shiga toxin to the endoplasmic reticulum. Nature 358: $510-512$.

Sansonetti PJ. 2011. To be or not to be a pathogen: That is the mucosally relevant question. Mucosal Immunol 4: 8-14.

Schmidt G, Sehr P, Wilm M, Selzer J, Mann M, Aktories K. 1997. Gln 63 of Rho is deamidated by Escherichia coli cytotoxic necrotizing factor-1. Nature 387: 725-729.

Shenker BJ, Dlakic M, Walker LP, Besack D, Jaffe E, LaBelle E, Boesze-Battaglia K. 2007. A novel mode of action for a microbial-derived immunotoxin: The cytolethal distending toxin subunit $\mathrm{B}$ exhibits phosphatidylinositol 3,4,5-triphosphate phosphatase activity. J Immunol 178: 5099-5108.

Taieb F, Nougayrede JP, Oswald E. 2011. Cycle inhibiting factors (Cifs): Cyclomodulins that usurp the ubiquitindependent degradation pathway of host cells. Toxins (Basel) 3: 356-368.

Torrino S, Visvikis O, Doye A, Boyer L, Stefani C, Munro P, Bertoglio J, Gacon G, Mettouchi A, Lemichez E. 2011. The E3 ubiquitin-ligase HACE1 catalyzes the ubiquitylation of active Rac1. Dev Cell 21: 959-965.

Visvikis O, Maddugoda MP, Lemichez E. 2010. Direct modifications of Rho proteins: Deconstructing GTPase regulation. Biol Cell 102: 377-389.

Weissman AM. 2001. Themes and variations on ubiquitylation. Nat Rev Mol Cell Biol 2: 169-178.

Worby CA, Mattoo S, Kruger RP, Corbeil LB, Koller A, Mendez JC, Zekarias B, Lazar C, Dixon JE. 2009. The Fic domain: Regulation of cell signaling by adenylylation. Mol Cell 34: 93-103.

Yarbrough ML, Li Y, Kinch LN, Grishin NV, Ball HL, Orth K. 2009. AMPylation of Rho GTPases by Vibrio VopS disrupts effector binding and downstream signaling. Science 323: $269-272$.

Zhang Y, Zhu X, Torelli AT, Lee M, Dzikovski B, Koralewski RM, Wang E, Freed J, Krebs C, Ealick SE, et al 2010. Diphthamide biosynthesis requires an organic radical generated by an iron-sulphur enzyme. Nature 465: 891-896. 


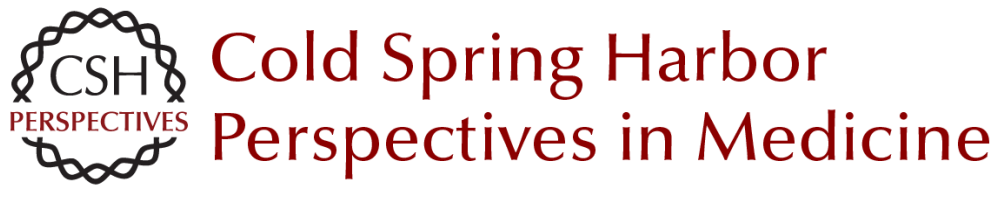

\section{General Aspects and Recent Advances on Bacterial Protein Toxins}

Emmanuel Lemichez and Joseph T. Barbieri

Cold Spring Harb Perspect Med 2013; doi: 10.1101/cshperspect.a013573

Subject Collection Bacterial Pathogenesis

Therapeutic and Prophylactic Applications of Bacteriophage Components in Modern Medicine Sankar Adhya, Carl R. Merril and Biswajit Biswas

Vaccines, Reverse Vaccinology, and Bacterial Pathogenesis Isabel Delany, Rino Rappuoli and Kate L. Seib

Helicobacter and Salmonella Persistent Infection Strategies Denise M. Monack

Echoes of a Distant Past: The cag Pathogenicity Island of Helicobacter pylori Nicola Pacchiani, Stefano Censini, Ludovico Buti, et al.

RNA-Mediated Regulation in Pathogenic Bacteria Isabelle Caldelari, Yanjie Chao, Pascale Romby, et al.

The Pneumococcus: Epidemiology, Microbiology, and Pathogenesis

Birgitta Henriques-Normark and Elaine I. Tuomanen

Pathogenesis of Meningococcemia Mathieu Coureuil, Olivier Join-Lambert, Hervé Lécuyer, et al.

Chlamydial Intracellular Survival Strategies Robert J. Bastidas, Cherilyn A. Elwell, Joanne N. Engel, et al.
Mechanisms and Biological Roles of

Contact-Dependent Growth Inhibition Systems

Christopher S. Hayes, Sanna Koskiniemi, Zachary

C. Ruhe, et al.

A Genome-Wide Perspective of Human Diversity and Its Implications in Infectious Disease Jérémy Manry and Lluis Quintana-Murci

Host Specificity of Bacterial Pathogens Andreas Bäumler and Ferric C. Fang

The Inside Story of Shigella Invasion of Intestinal Epithelial Cells

Nathalie Carayol and Guy Tran Van Nhieu

Bartonella and Brucella--Weapons and Strategies for Stealth Attack

Houchaima Ben-Tekaya, Jean-Pierre Gorvel and Christoph Dehio

Concepts and Mechanisms: Crossing Host

Barriers

Kelly S. Doran, Anirban Banerjee, Olivier Disson, et al.

Genome Dynamics in Legionella: The Basis of

Versatility and Adaptation to Intracellular

Replication

Laura Gomez-Valero and Carmen Buchrieser

Mechanisms of Francisella tularensis Intracellular

Pathogenesis

Jean Celli and Thomas C. Zahrt

For additional articles in this collection, see http://perspectivesinmedicine.cshlp.org/cgi/collection/ 